\title{
Texture design of gluten-free bread by mixing under controlled headspace atmosphere
}

\author{
Sabina Paulik ${ }^{1}$ (1) $\cdot$ Christoph Paczkowski ${ }^{1} \cdot$ Rita Laukemper $^{1} \cdot$ Thomas Becker $^{1} \cdot$ Mario Jekle $^{1}$
}

Received: 3 February 2021 / Revised: 4 June 2021 / Accepted: 5 June 2021 / Published online: 19 June 2021

(c) The Author(s) 2021

\begin{abstract}
Gluten-free breads often show a reduced specific bread volume, in comparison to gluten-containing products, caused by non-adapted processing technologies of gluten-free dough. In this investigation, different mixing speeds and durations (600-3000 rpm for $3 \mathrm{~min}, 5 \mathrm{~min}$ or $8 \mathrm{~min}$, respectively) as well as variations in the pressure $\left(p_{\text {rel }}-50\right.$ to $\left.p_{\text {rel }}+130 \mathrm{kPa}\right)$ in the headspace atmosphere during mixing (Stephan mixer) and pressure ratios of overpressure/negative pressure of 8 min mixing $(20 / 80,50 / 50,80 / 20)$ were studied to determine their impact on the gas volume fraction of dough and specific volume of breads. A pressure rise of $p_{\text {rel }} 50 \mathrm{kPa}, p_{\text {rel }} 100 \mathrm{kPa}$ or $p_{\text {rel }} 130 \mathrm{kPa}$ increased the gas volume fraction in dough of $60 \%, 100 \%$ or $120 \%$, respectively, and led to a significant higher specific bread volume (7\%) and the reduction of crumb hardness (35\%) at $p_{\text {rel }} 130 \mathrm{kPa}$. A linear correlation $\left(R^{2}=0.843\right)$ between the pressure and specific volume of breads was found. An extended first mixing phase at overpressure resulted in the formation of a very fine pore structure, whereby a short overpressure phase caused the formation of big pores. Thus, the control of the headspace atmosphere during mixing is a suitable parameter to adjust the density of dough and consequently, the pore size distribution for a specific texture design.
\end{abstract}

Keywords Gas distribution $\cdot$ Dough density $\cdot$ Rice starch $\cdot$ Structure-function relation $\cdot$ Starch hydration $\cdot$ Kneading

\section{Introduction}

The finale volume of baked goods depends on the gas production or gas entrapment of dough, as well as the gas stabilization during dough preparation and baking process [1, 2]. Long time, scientific focus was on the optimization of gas stabilization in gluten-free (gf) dough, for instance by the addition of hydrocolloids or other functional polymers to the bulk phase, as well as the improvement of the hydration properties of dough [3-7]. In recent approaches, the finale gas volume ratio of gf breads is optimized by focusing on the gas introduction in gf dough by the adaption of the mixing process [8] or extrusion processes [9]. Since gf dough resembles cake batters in its functional properties [10], the finale gas volume of baked goods (37-73\%) strongly depends on the mixing process $[8,11]$. Even if the stabilization of gas bubbles differs tremendously between cake and

Mario Jekle

mjekle@tum.de

1 Institute of Brewing and Beverage Technology, Research Group Cereal Technology and Process Engineering, Technical University of Munich, 85354 Freising, Germany dough systems, an early incorporation of a high proportion of gas into the liquid dough could be advantageous. This applies especially for the mentioned liquid dough types, since these have no intermediate forming and shaping step, in which the incorporated gas from the mixing process would be re-distributed. Studies on these gf dough types showed an increased finale volume of gf bread by $12-21 \%$ [12] by varying process parameters, as mixing speed and time, or the geometry of mixers, or introduction of novel heating methods, as Ohmic heating [13]. However, a further crucial factor - the headspace atmosphere (HSA) — was, to the best of our knowledge, not studied so far.

In wheat-based dough and baked goods, the application of a modified HSA (for instance in Chorleywood-kneaders) already showed positive changes in the number and distribution of gas nuclei and later bubbles in dough $[14,15]$, resulting in significant alterations of the pore structure [16] and consequently the bread volume:

- Kneading above atmospheric pressure generated gas bubbles, which did expand at atmospheric pressure.

- Kneading below atmospheric pressure caused the expansion of gas bubbles, which could easily be dis- 
persed during kneading and which contracted at subsequent atmospheric pressure [17].

Beside the amount of gas bubbles in dough or pores in bread, the gas bubble distribution/size and pore structure (open cell/closed cell) in crumbs significantly affect the sensory of the product [18] and a homogenous distribution of bubbles is a requirement for most high-quality baked goods.

In wheat-based dough, a modified HSA can cause further changes of gluten proteins and its network formation by altering its chemical structure. This complicates the precise elucidation of the impact of the mechanical gas entrapment in dough and its influence on the finale bread sensory, especially since the effects of the modified HSA strongly depend on the used flour quality [19].

The usage of starch-based dough, among these glutenfree (gf) dough, overcomes the challenges of a possible chemical gluten modification caused by a modified HSA and enables new findings on the impact of modified HSA on the crumb texture. The knowledge of underlying mechanisms allows a better control of the bread crumb structure and finally quality of gf breads.

In the present study, the impact of extrinsic mixing parameters on the amount, size and distribution of gas bubbles in rice-based gluten-free (gf) dough and bread were determined. First, the impact of mixing time and speed was studied on the gas distribution, the final gas volume fraction in breads and its crumb hardness. Second, changes of dough density and bread volume at a modified headspace atmosphere (HSA) during mixing were investigated by means of an $\mu$-CT-analysis of the crumb and a crumb density measurement. The purpose of the study was to investigate the effects of a controlled headspace atmosphere on the mechanical entrapping of gas in gluten-free dough and their mechanical distribution for a propertydriven texture design of gluten-free food.

\section{Materials and methods}

\section{Preparation of dough and bread}

Dough were made in the UMSK 24 mixer of Stephan Machinery GmbH (Hameln, Germany). The mixing speed was set in a range of 300-3000 rpm and the relative pressure $p_{\text {rel }}$ was adapted between 130 (overpressure) and $-80 \mathrm{kPa}$ (negative pressure) (absolute pressure range $20-230 \mathrm{kPa})$.

The following experimental setups were performed and analyzed to enhance the gas volume fraction in gluten-free dough and bread:
- Mixing speed and time during dough preparation: mixing speed was varied between 600 and $3000 \mathrm{rpm}$ for $3 \mathrm{~min}$, $5 \mathrm{~min}$ or $8 \mathrm{~min}$, respectively.

- Pressure of headspace atmosphere (HSA): relative pressure (difference between actual pressure during mixing and atmospheric pressure) of HSA ranged between -50 and $+130 \mathrm{kPa}$ (maximum pressure range for the used mixer) at mixing speeds of $1800 \mathrm{rpm}, 2400 \mathrm{rpm}$ and $3000 \mathrm{rpm}$ for $5 \mathrm{~min}$ or $8 \mathrm{~min}$, respectively.

- Combinations of the pressure of the headspace atmosphere (HSA): combination of first and second mixing phase: 20/80 (96 s/384 s), 50/50 (240 s/240 s), 80/20 (384 s/96 s). First mixing phase was always performed with an overpressure $\left(p_{\text {rel }} 130 \mathrm{kPa}\right)$ at $3000 \mathrm{rpm}$. Negative pressure of the second mixing phase was $-80 \mathrm{kPa}$, $-50 \mathrm{kPa}$ or $-20 \mathrm{kPa}$, respectively.

Dough were prepared in triplicates using rice flour (moisture determined by a moisture analyzer DAB or MLB 50-3, Kern \& Sohn GmbH, Balingen, Germany) from Müller's Mühle GmbH (Gelsenkirchen, Germany), with the addition of demineralized water (120 g $100 \mathrm{~g}^{-1}$ flour), margarine (3 g $100 \mathrm{~g}^{-1}$ flour, CSM Deutschland $\mathrm{GmbH}$, Bingen am Rhein,

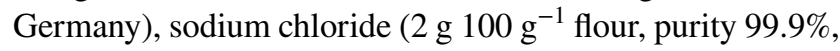
Südsalz GmbH, Heilbronn, Germany), D(+)-glucose (2 g $100 \mathrm{~g}^{-1}$ flour, ApliChem GmbH, Darmstadt, Germany), Methocel $^{\mathrm{TM}}$ (Hydroxypropylmethylcellulose (HPMC) (2 g $100 \mathrm{~g}^{-1}$ flour, Dow Wolff Cellulosics GmbH, Bomlitz, Germany) and dry yeast Fermipan red (2 g $100 \mathrm{~g}^{-1}$ flour, Casteggio Lieviti srl, Casteggio, Italy). The final water content was adjusted to the flour moisture content $\left(14{\mathrm{~g} 100 \mathrm{~g}^{-1}}^{-1}\right.$ flour) according to ICC 110/1. The temperature of added water is calculated using the following formula (modified to Cauvain et al. [20]), so that a final temperature of the dough of $26 \pm 1{ }^{\circ} \mathrm{C}$ was achieved:

$T_{\text {water }}=1.35 * T_{\text {dough start }}-T_{\text {flour }}$.

The ingredients were mixed for $60 \mathrm{~s}$ at $300 \mathrm{rpm}$, prior starting the testing experiments. The mixing speed, mixing time, headspace pressure and pressure combinations were varied. The mixing vessel was cooled through a double shell during the whole mixing process and the initial temperature of dough was varied to ensure a constant final temperature of dough under $26 \pm 1{ }^{\circ} \mathrm{C}$ (compare Table 1). The temperature rise for each experiment is shown in the supplementary data (Fig. 1), which was the prerequisite to calculate the initial temperature.

After mixing, the density of the dough was measured (compare 2.3). Simultaneously, the dough was separated into eight pieces of $220 \mathrm{~g}$. 4 pieces were placed in greased baking pans before resting in a proofing chamber CDS Sun Riser (KOMA GmbH (Roermond, Netherlands) at $30{ }^{\circ} \mathrm{C}$ 
Table 1 Initial temperature of ingredient blends in the mixer for each experiment to reach a final dough temperature of $26 \pm 1{ }^{\circ} \mathrm{C}$ after mixing

\begin{tabular}{lll}
\hline Mixing speed $(\mathrm{rpm})$ & Mixing time $(\mathrm{min})$ & $\begin{array}{l}\text { Initial } \\
\text { temperature } \\
\left({ }^{\circ} \mathrm{C}\right)\end{array}$ \\
\hline 600 & 5 & $23.1 \pm 1.4$ \\
600 & 8 & $23.1 \pm 0.8$ \\
1200 & 5 & $21.7 \pm 1.2$ \\
1200 & 8 & $19.5 \pm 0.9$ \\
1800 & 5 & $20.7 \pm 1.5$ \\
1800 & 8 & $18.6 \pm 0.2$ \\
2400 & 5 & $20.4 \pm 1.6$ \\
2400 & 8 & $17.5 \pm 1.5$ \\
3000 & 5 & $18.8 \pm 1.9$ \\
3000 & 8 & $15.1 \pm 0.4$ \\
\hline
\end{tabular}

with $80 \%$ relative humidity for $45 \mathrm{~min}$ (standard proofing). Afterward, the pieces were baked in a Matador 12.8 oven (Werner \& Pfleiderer Lebensmitteltechnik GmbH, Dinkelsbühl, Germany) for $35 \mathrm{~min}$ at $220{ }^{\circ} \mathrm{C}$ upper heat, $230{ }^{\circ} \mathrm{C}$ bottom heat with $0.69 \mathrm{~L}$ initial steam and a $100 \%$ setting of the humidity draught. After cooling at $20 \pm 2{ }^{\circ} \mathrm{C}$ for $150 \mathrm{~min}$, the specific bread volume $\left(\mathrm{cm}^{3} \mathrm{~g}^{-1}\right)$ was analyzed (compare settings in chapter 2.2).

\section{Analysis of dough and breads}

\section{Gas volume fraction}

The determination of the gas volume fraction requires the knowledge of the gas free dough density. Thus, the yeastleavened dough was centrifuged at $4000 \mathrm{rpm}$ for $20 \mathrm{~min}$ at room temperature, to degas the dough, and to determine the volume of the gas free dough ( $\left.V_{\text {dough gas free }}\right)$. The density of the gas free dough is calculated using the following formula:

$\rho_{\text {gas free }}=\frac{m_{\text {dough gas free }}}{V_{\text {dough gas free }}}$,

where $m_{\text {dough gas free }}$ is the weight of the dough, $V_{\text {dough gas free }}$ is the volume of the gas free dough and $p_{\text {gas free }}$ is the density of gas free dough.

The volume of the gas containing dough was determined by filling a defined dough volume into a beaker $(100 \mathrm{ml}$ CSM Deutschland GmbH, Bingen am Rhein, Germany) and determining the weight (the following formula):

$\rho_{\text {with gas }}=\frac{m_{\text {dough }}}{V_{\text {dough with gas }}}$,

where $m_{\text {dough with gas }}$ is the weight of the gas containing dough, $V_{\text {dough with gas }}$ is the volume of the containing dough and $p_{\text {with gas }}$ is the density of gas containing dough.

The percentage of the gas volume fraction $\varphi$ is calculated with the following formula:

$\varphi=\left[1-\left(\frac{\rho_{\text {dough gas free }}}{\rho_{\text {dough with gas }}}\right)\right] * 100$.

\section{Specific bread volume}

The specific bread volume was determined after $2.5 \mathrm{~h}$ of standardized cooling, using TexVol BVM-L370 (Perten Instruments, Sweden). Weighed breads (precision weight PCB, Kern \& Sohn GmbH, Balingen, Germany) were clamped on a rotating bracket. The bread surface was
Fig. 1 Diagram for the calculation of the initial temperature

\section{Initial temperature}

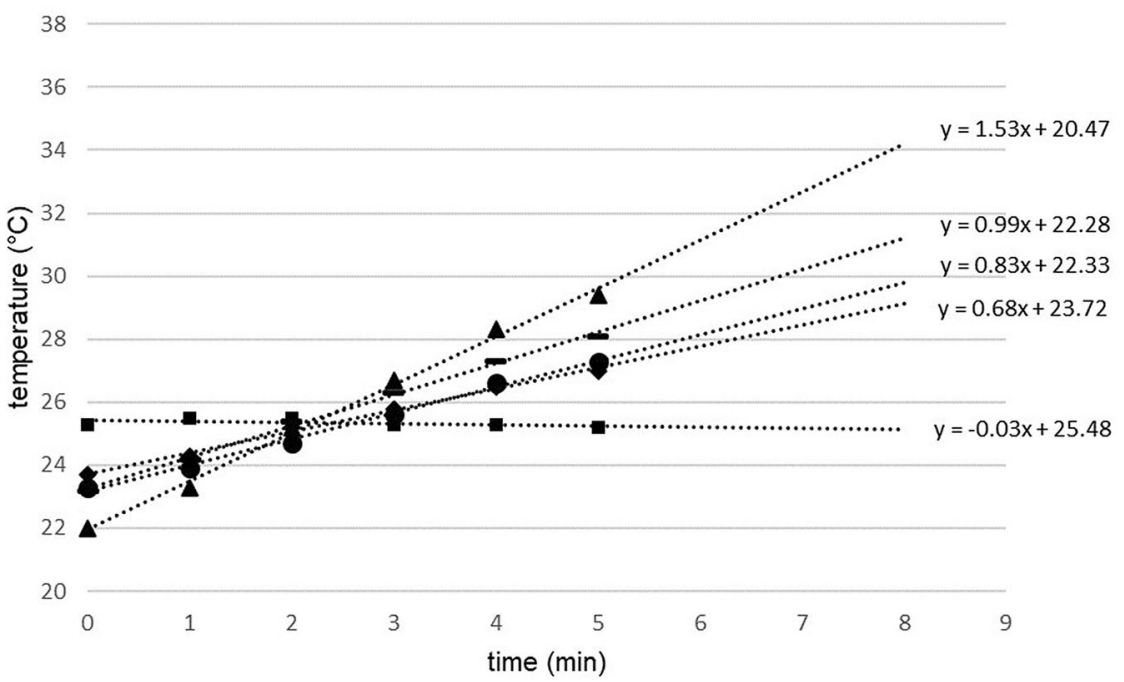

-600rpm

-1200rpm

-2400rpm

-1800rpm

A 3000rpm 
scanned by a laser to evaluate the bread volume. Based on these results, the specific bread volume (volume/weight) was determined.

\section{Crumb hardness}

The crumb hardness was analyzed after $2.5 \mathrm{~h}$ of cooling using the texture analyzer Tex Vol Instrument $\mathrm{f} 300 \times$ (Perten Instruments, Sweden)). At first, two round discs of $15 \mathrm{~mm}$ were cut out the crumb with a sharp, jagged drilling head (Ritterwerk, Gröbenzell, Germany) without squeezing the crumb and rejected. The following bread slices were used for the analysis. Therefore, two discs $(25 \mathrm{~mm}$ height, each $12.5 \mathrm{~mm}$ ) were placed for compression (diameter: of stamp $20 \mathrm{~mm}$ ). The crumb discs were compressed by $40 \%$ with a test speed of $1.7 \mathrm{~mm} \mathrm{~s}^{-1}$, a post-test speed of $1.0 \mathrm{~mm} \mathrm{~s}^{-1}$, and a trigger force of $0.049 \mathrm{~N}$. The crumb hardness corresponds to the peak force of the first compression cycle.

\section{Distribution of pores in crumb}

A $12.5 \mathrm{~mm}$ crumb slice was photographed at standardized light conditions using a self-constructed photo box and the program Pylon Viewer $(\times 64)$.

\section{$\mu \mathrm{CT}$ measurement}

The non-destructive $\mu \mathrm{CT}$ measurement enables the analysis of the gas bubble distribution in dough and breads, as well as the determination of the dough density without gas. The 3D $\mu \mathrm{CT}$ measurement was performed of dough (without yeast) and breads, prepared with yeast using a portable CT system (CTportable 160.90) with the dimension $(0.770 \mathrm{~m} \times 0.375 \mathrm{~m} \times 0.550 \mathrm{~m}(\mathrm{~L} \times \mathrm{W} \times \mathrm{H})$. The resolution area was between 2 and $40 \mu \mathrm{m}$. Small portions of dough were taken carefully with a specifically manufactured centrifuge tube, whereby shearing of the dough was tried to keep minimal. To analyze the breads, the end of the bread $(15 \mathrm{~mm})$ was removed. Afterwards, a $20 \mathrm{~mm}$ thick bread slice was cut. A piece of crumb was punched with a cylinder (Ø $30 \mathrm{~mm}$ ), which was analyzed, after performing a white balance. Samples were analyzed at the Fraunhofer Institute for Integrated Circuits IIS using the method of Eggert [21].

\section{Statistical analysis}

Statistical analysis was performed using JMP Pro (Version JMP Pro 12.2., JMP Software, SAS Institute Inc., Cary, NC, USA). Significant differences were determined using Tukey's pairwise comparison (confidence level of 95\%) with ANOVA.

\section{Results and discussion}

\section{Impact of mixing speed and time}

\section{Gas entrapment in dough}

The impact of mixing speed and time on the gas entrapment in dough was analyzed to determine suitable mixing parameters prior varying the headspace atmosphere (HSA). The results of three different mixing durations ( $3 \mathrm{~min}, 5 \mathrm{~min}$ and $8 \mathrm{~min}$ ), as well as five mixing speeds (600 rpm, $1200 \mathrm{rpm}$, $1800 \mathrm{rpm}, 2400 \mathrm{rpm}$ and $3000 \mathrm{rpm}$ ) are shown in Fig. 2.

A prolonged mixing duration from 3 to $8 \mathrm{~min}$ led to a significant decrease in gas volume fraction. Furthermore, the increase in mixing speed from 600 to $1200 \mathrm{rpm}$ caused a significant reduction in gas volume fraction of the dough for all three mixing durations ( $3 \mathrm{~min}, 5 \mathrm{~min}$ and $8 \mathrm{~min}$ ). This result was unexpected, since the authors anticipated a rise in gas volume fraction of the dough with increase in mixing speed, as noticed by the authors Gómez et al. [22]. The incomplete homogenization of the dough at such low
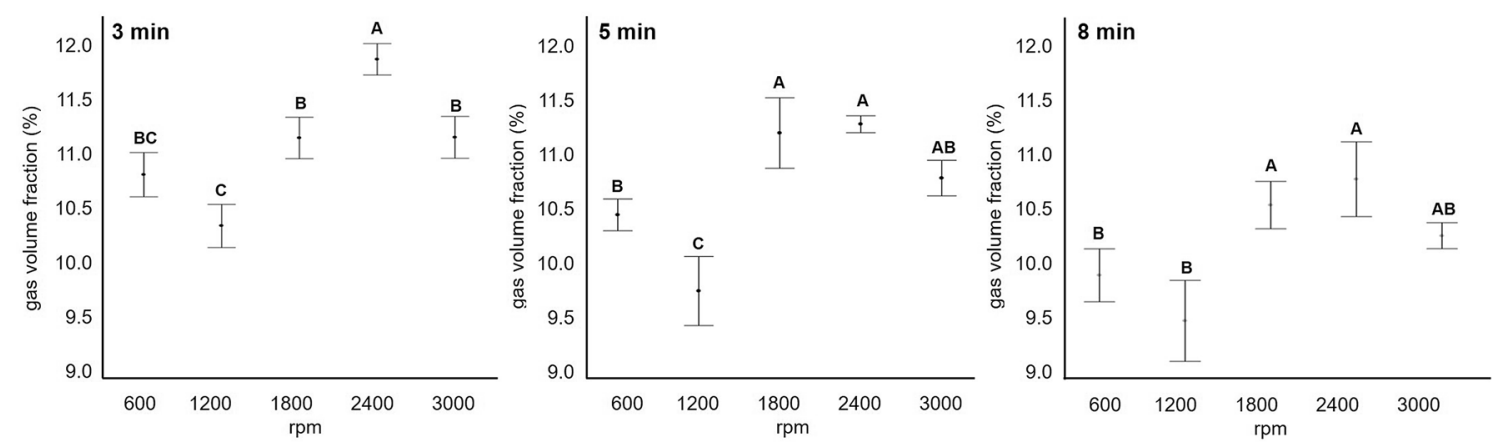

Fig. 2 Impact of mixing speed on gas volume fraction of gluten-free dough at a mixing time of 3 (left), 5 (middle) or 8 (right) min, respectively. Final dough temperature was set to $26 \pm 1{ }^{\circ} \mathrm{C}$. Mean \pm std.,

$n=3$. Different letters demonstrate significant differences in gas volume fraction of dough $(p$ values $<0.05)$, identified by one-way ANOVA Tukey Test 
mixing speeds could explain the unexpected gas volume development, since massive sediments were visible on mixing elements. These sediments could affect the density of the dough, provoking variations in the gas volume fraction. A further increase in mixing speed up to $2400 \mathrm{rpm}$ resulted in a significant rise in a gas volume fraction of the dough of $8.8 \%, 8.2 \%$ and $8.8 \%$ for a $3 \mathrm{~min}, 5 \mathrm{~min}$ and $8 \mathrm{~min}$ mixing process, respectively, in comparison to a mixing at $600 \mathrm{rpm}$. A final gas volume fraction (at $2400 \mathrm{rpm}$ ) of $12.0 \pm 0.1 \%$, $11.3 \pm 0.1 \%$ and $10.9 \pm 0.2 \%$ was achieved for $3 \mathrm{~min}, 5 \mathrm{~min}$ and 8 min mixing, respectively. For all mixing durations, the measured gas volume was above the known rise in gas volume fraction for gluten-free (gf) yeast-free dough (4-8\%), as summarized by Campbell and Mougeot [11]. Consequently, the used mixer and the recipe was suitable to produce low density gf dough and could used for further experiments with altered headspace atmosphere (HAS).

A further rise in mixing speed up to $3000 \mathrm{rpm}$ resulted in a reduction in gas volume fraction of the dough (statistically significant for $3 \mathrm{~min}$ mixing). On the one hand, the high mixing speed - thus mixing forces—at $3000 \mathrm{rpm}$, could evoke the destruction of gas-stabilizing dough structures, which were built by a HPMC network and/ or swollen starch granules. This is already known from cake batters or glutencontaining dough, where covalent bonds of gluten were fragmented at a high mixing speed [23]. On the other hand, high rotation speeds during mixing could cause an increase in dough temperature altering the gas cell stability. The negative effects on the gas volume fraction caused by a higher shear stress was also shown, when dough mixing durations are compared: the gas volume fraction of the dough decreased significantly by $9.5 \%$ with increase in mixing time from 3 to $8 \mathrm{~min}$ (at $600 \mathrm{rpm}$ ). This effect arises especially for

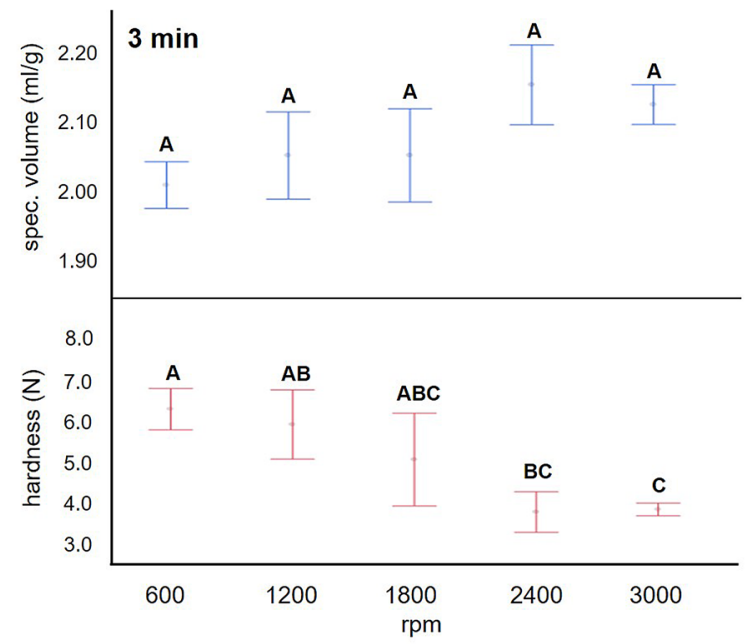

Fig. 3 Impact of mixing speed on the specific gluten-free bread volume and crumb hardness at a mixing time of 3 (left) or 8 (right) min, respectively. Mean \pm std., $n=3$. Different letters demonstrate signifi- higher mixing speeds ( $2400 \mathrm{rpm}$ and $3000 \mathrm{rpm}$ ), which is in accordance to findings in cake batters [24]. Consequently, destroyed gas-stabilizing dough structure and altered temperatures during mixing can affect the gas entrapment in gluten-free dough at higher mixing speeds. Profound studies using time domain (TD) NMR and scanning electron microscopy (SEM) would contributed to a detailed elucidation of the cell structure and water distribution of gf cake batters and bread [25].

\section{Baking performance based on varied mixing parameters}

The final density of breads is determined by the mechanical gas entrapment during dough preparation, the gas production by the chemical or biological leavening of dough and the bulk-dependent gas stabilization during dough preparation and thermal transition of the biopolymers during baking [26]. For a mixing time of $3 \mathrm{~min}$, the mean specific bread volume varied between $2.01 \mathrm{ml} / \mathrm{g}(600 \mathrm{rpm})$ and $2.15 \mathrm{ml} / \mathrm{g}$ (2400 rpm) for mixing speed between 600 and $3000 \mathrm{rpm}$ (not significant, $p$ values $<0.05$ ) (compare Fig. 3, top). In general, alterations of the crumb hardness are accompanied inversely proportional to the rise in specific volume and decrease with increase in specific volume [27]. Although no statistically significant rise in specific bread volume was noticed, a significant reduction in crumb hardness occurred from $636.4 \pm 45.6 \mathrm{~N}$ (600 rpm, $3 \mathrm{~min}$ mixing duration) to $397.2 \pm 13.1 \mathrm{~N}$ (3000 rpm, 3 min mixing duration) (Fig. 3, bottom). Thus, a low mixing duration in combination with a high rotation speed caused the development of softer and more elastic crumbs. Since no significant alterations of the specific loaf volume occurred, the reduced crumb hardness can be lead back to a modified dough structure formation

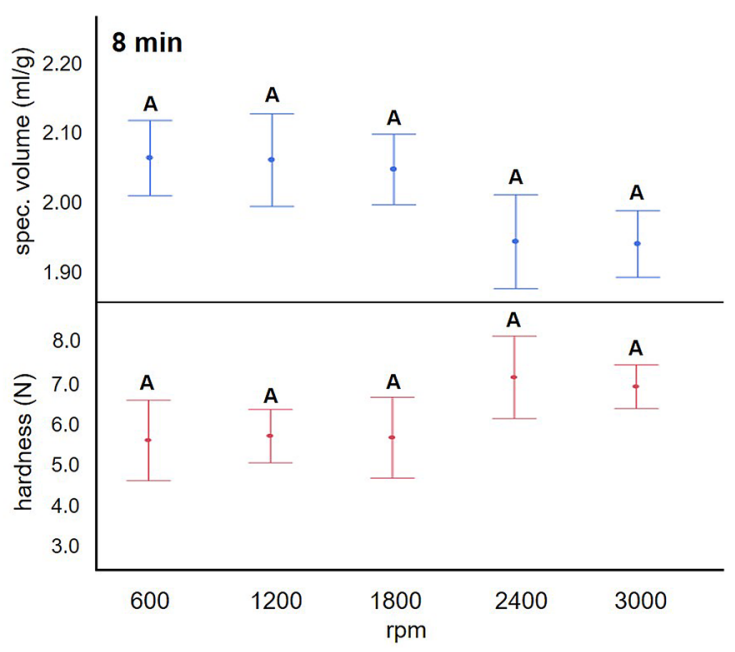

cant differences in specific bread volume or crumb hardness ( $p$ values $<0.05$ ), identified by one-way ANOVA Tukey Test 
during mixing, and consequently, crumb structure formation during baking, evoking desired quality characteristics for gluten-free and gluten-containing breads.

For a mixing duration of $8 \mathrm{~min}$, however, no statistically significant $(p$ values $<0.05$ ) alterations of the specific bread volume (Fig. 3, top) and crumb hardness (Fig. 3, bottom) were noticed within the mixing speed of 600-3000 rpm. The specific bread volume ranged between $2.07 \pm 0.05 \mathrm{ml} / \mathrm{g}$ $(600 \mathrm{rpm})$ and $1.94 \pm 0.05 \mathrm{ml} / \mathrm{g}$ (3000 rpm). A tendency to decrease with increase in mixing speed was also noticed by Gómez et al. [22] for the specific loaf volume of gf bread (hydration level 110\%). Tan et al. [28] noted a steadily increase in crumb hardness with increase in mixing speed for cake batters, which is in accordance to our results, and an optimum for a mediate mixing time of $9 \mathrm{~min}$. However, due to differences in the batter formulation and mixing geometry, results of Gómez et al. [22] and Tan et al. [28] are not directly transferable to our study.

Despite the possibility to improve the specific volume of gf breads by altering the mixing time and speed, the specific volume of gf breads was still lower in comparison to glutencontaining wheat bread $(3.3-3.7 \mathrm{ml} / \mathrm{g})$ [29]. Thus, further changes in process parameters were necessary to improve the quality (especially the specific volume) of gluten-free bread.

Beside the specific bread volume and the crumb hardness, the pore size and pore distribution are important quality parameters for gluten-free dough, whereby a uniform distribution of pores is preferred. Crumb pores got finer (with sporadic bigger pores) for a 3 min mixing, when the mixing speed was increased from 600 to $1200 \mathrm{rpm}$ (Fig. 4). This was in accordance with the results of the gas volume fraction in dough, where a decrease in gas volume was noticed with the rise in mixing speed from 600 to $1200 \mathrm{rpm}$. The further rise in mixing speed up to $2400 \mathrm{rpm}$ caused the formation of uniform, bigger pores. Thus, the higher mixing speed enabled a homogeneous pore size distribution. Furthermore, the bigger pores led to a lowered crumb hardness at high mixing speeds of 2400 and $3000 \mathrm{rpm}$. The combination of a high mixing speed and mixing time $(8 \mathrm{~min})$ resulted in the formation of very small pores, most likely since the increase in mixing time caused the dispersion of gas bubbles in the dough. Consequently, the partial pressure of each gas bubble increased, impeding the presence of $\mathrm{CO}_{2}$ (produced in yeast-leavened dough) in the gas state. In addition, the higher shear stress could destroy a gas-stabilizing network in dough causing an impaired gas stabilization in dough, as mentioned before.

Despite good results for the specific bread volume at a mixing time of $3 \mathrm{~min}$, the authors decided not to use this low mixing duration for further experiments. A homogeneous distribution of components could not be ensured during mixing and massive sediments were visible on mixing elements. The same applied for low mixing speeds of $600 \mathrm{rpm}$ and $1200 \mathrm{rpm}$, which were also excluded for further experiments. Experiments at varying headspace atmospheres (two-phase mixing) were, therefore, performed at $3000 \mathrm{rpm}$.

Although the adaption of mixing parameters, as speed and duration, could improve the gas volume fraction in dough,

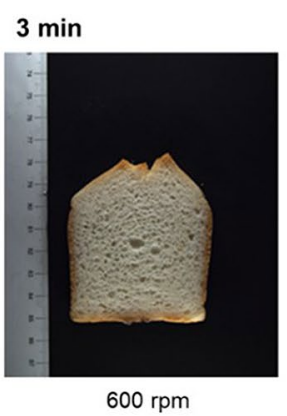

$8 \min$

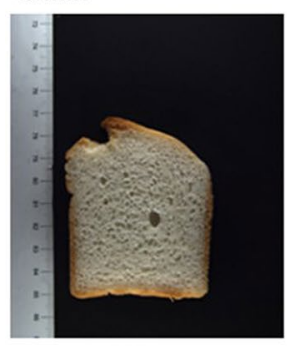

$600 \mathrm{rpm}$

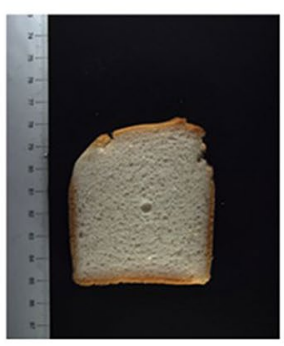

$1200 \mathrm{rpm}$

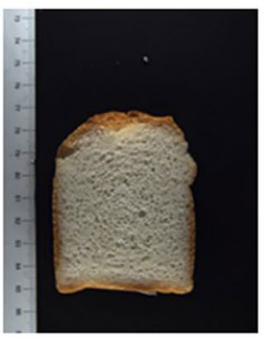

$1200 \mathrm{rpm}$

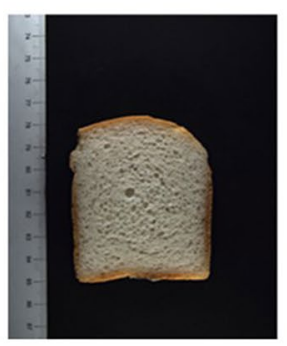

$1800 \mathrm{rpm}$

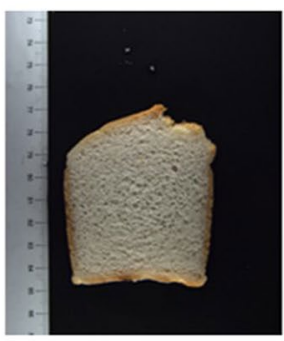

$1800 \mathrm{rpm}$

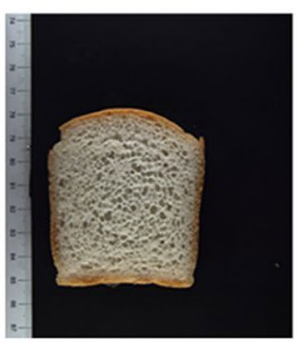

$2400 \mathrm{rpm}$

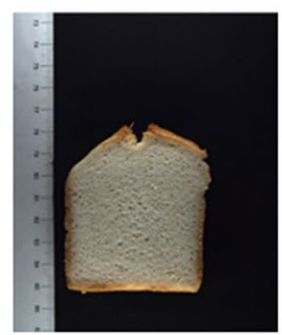

$2400 \mathrm{rpm}$

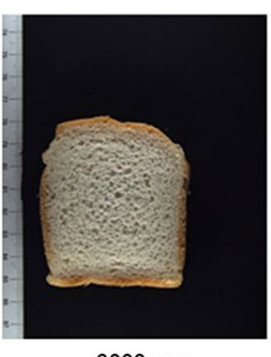

$3000 \mathrm{rpm}$

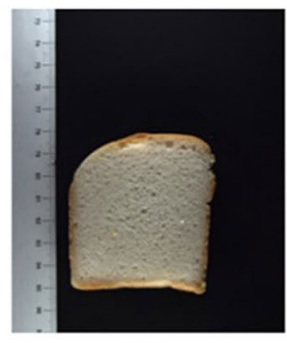

$3000 \mathrm{rpm}$

Fig. 4 Distribution of pores in gluten-free crumb at mixing speeds of $600,1200,1800,2400,3000$ rpm and mixing durations of 3 (up) or 8 (down) min, respectively 
these parameters were not adequate to achieve a satisfying specific bread volume, comparable with gluten-containing wheat bread. Thus, further focus was on the impact of the headspace atmosphere and their effects on the gas volume fraction in dough and the specific bread volume.

\section{Impact of headspace atmosphere pressure during mixing -1 phase mixing}

The effects of a pressure increase or pressure decline in the headspace atmosphere (HSA) during mixing was analyzed in the following chapter (results are displayed in Fig. 5). All pressure values are described as relative pressure in comparison to the atmospheric pressure, which is the normal pressure during mixing. Thus, the relative pressure is the difference between the pressure, which was present during mixing, and the atmospheric pressure $\left(p_{\text {rel }} 0 \mathrm{kPa}\right)$, with an overpressure of $p_{\text {rel }}>0 \mathrm{kPa}$ and a negative pressure of $p_{\text {rel }}<0 \mathrm{kPa}$.

The mixing speed showed only little effects (no significant effects between mixing speed $2400 \mathrm{rpm}$ and $3000 \mathrm{rpm}$ ) on the gas volume fraction of gluten-free dough, in comparison to pressure changes in the HAS: the pressure rise of $50 \mathrm{kPa}\left(p_{\text {rel }} 50 \mathrm{kPa}\right), 100 \mathrm{kPa}\left(p_{\text {rel }} 100 \mathrm{kPa}\right)$ or $130 \mathrm{kPa}$ $\left(p_{\text {rel }} 130 \mathrm{kPa}\right)$ enabled a significant, relative increase in gas volume fraction of $52 \%, 100 \%$ or $120 \%$ (at $2400 \mathrm{rpm}$ ), respectively. As a result, the specific volume increased by $9 \%$, leading to a reduction of crumb hardness by $45 \%$ (at $p_{\text {rel }} 130 \mathrm{kPa}, 2400 \mathrm{rpm}$ ). This behavior was also demonstrated for a mixing speed of $600 \mathrm{rpm}$ and $3000 \mathrm{rpm}$. Otherwise, the reduction of pressure $\left(p_{\text {rel }}<0 \mathrm{kPa}\right)$ in comparison to a mixing process at atmospheric pressure caused a degassing of the dough (significant reduction in gas volume fraction) and consequently a lowering of the specific bread volume and the rise in crumb hardness. Thus, overpressure or negative pressure modifies the gas entrapment in dough and additionally the dough rheology resulting in a modified crumb characteristic [14].

The $\mu$-CT-analysis confirmed these findings of the gas volume fraction measurement and the analysis of the bread crumb (Fig. 6): with the increase in overpressure the volume of gas bubbles in dough increased, whereby the increase in gas fraction in dough could be transferred over the whole process into the crumb structure. The expansion of gas bubbles caused the formation of a finer lamellar structure, which, in turn, possibly stabilized the gas bubbles.

Figure 7 clarifies the relation of the pressure of the HSA $\left(p_{\text {rel }}-80\right.$ to $p_{\text {rel }} 130 \mathrm{kPa}$ ), the dough density and its impact on the specific volume of gluten-free breads:

- The dough density increased with decrease in pressure from $p_{\text {rel }}+130 \mathrm{kPa} \rightarrow p_{\text {rel }}-80 \mathrm{kPa}$.

- The bread volume decreased with increase in dough density.

To achieve highly inflated gluten-free breads, the mixing pressure should be kept high (to prevent a degassing of the dough) and to increase the volume of the product.

\section{Impact of headspace atmosphere pressure variations during mixing -2 phase mixing}

Based on the significant impact of the pressure of the headspace atmosphere (HSA) on the dough density and bread quality from the previous chapter, the effects of a two-phase mixing process, including a overpressure and negative pressure mixing step, were analyzed. The aim of the two-phase mixing process was to increase the gas entrapment in the dough during the first phase of mixing (overpressure) and to stretch the gas bubbles by applying negative pressure in the second mixing phase, so that they can easily be dispersed by the shear forces during mixing
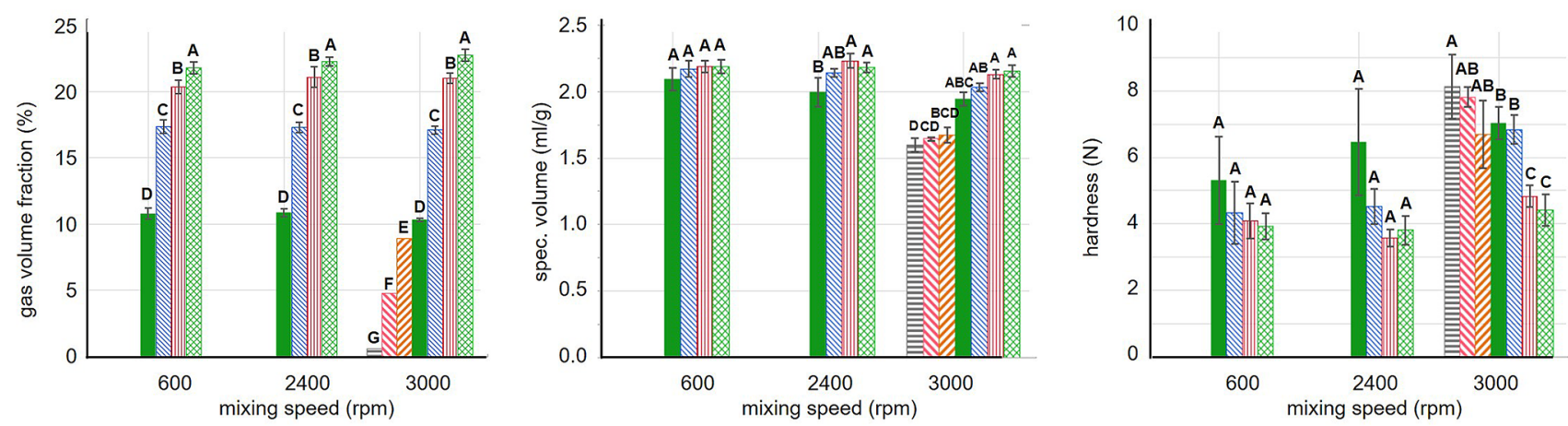

Fig. 5 Impact of mixing speed and headspace atmosphere pressure (relative pressure compared to atmospheric pressure) for a 8 min mixing process on gas volume fraction (left), specific bread volume (middle) and crumb hardness (right) $\equiv p_{\text {rel }}-80 \mathrm{kPa}$, NW $\mathrm{p}_{\text {rel }}-50 \mathrm{kPa}$,
W/A $\mathrm{p}_{\text {rel }}-20 \mathrm{kPa}, \quad p_{\text {rel }} 0 \mathrm{kPa}$, IIII $p_{\text {rel }} 50 \mathrm{kPa},\|\|\|\| \| p_{\text {rel }} 100 \mathrm{kPa}$, and $p_{\text {rel }} 130 \mathrm{kPa}$ ). Mean \pm std., $n=3$. Different letters demonstrate significant differences in gas volume fraction ( $p$ values $<0.05)$, identified by one-way ANOVA Tukey Test 


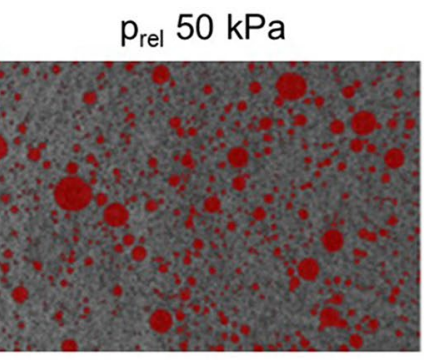

$\mathrm{p}_{\text {rel }} 50 \mathrm{kPa}$

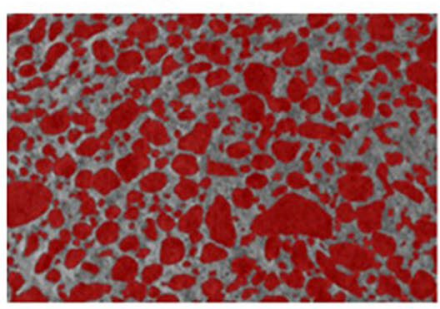

dough

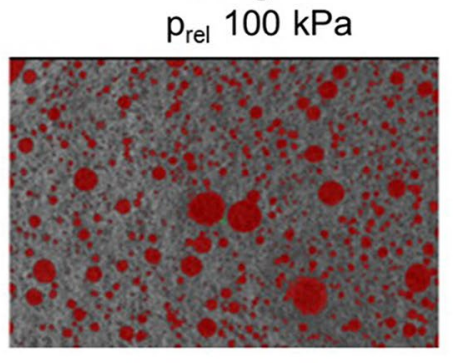

crumb

$\mathrm{p}_{\text {rel }} 100 \mathrm{kPa}$

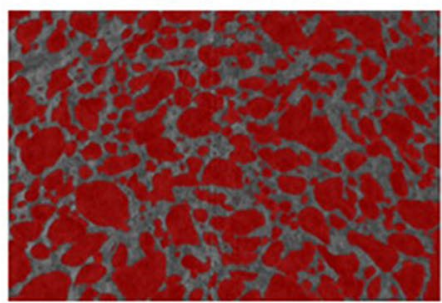

$p_{\text {rel }} 130 \mathrm{kPa}$

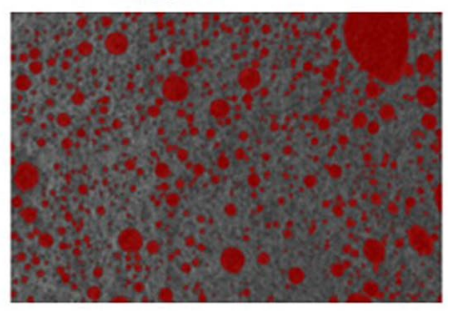

$p_{\text {rel }} 130 \mathrm{kPa}$

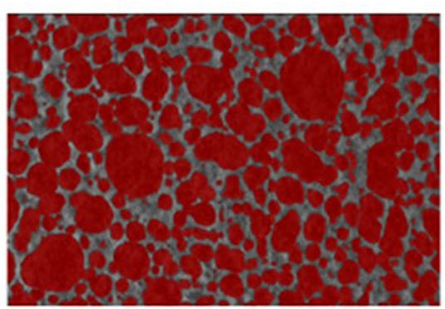

Fig. $6 \mu$-CT-analysis of gluten-free dough and crumbs prepared at overpressure of headspace atmosphere at $p_{\text {rel }} 50 \mathrm{kPa}, p_{\text {rel }} 100 \mathrm{kPa}$ and $p_{\text {rel }}$ $130 \mathrm{kPa}$ (3000 rpm, $8 \mathrm{~min}$ ). Detected gas bubbles are shown in red

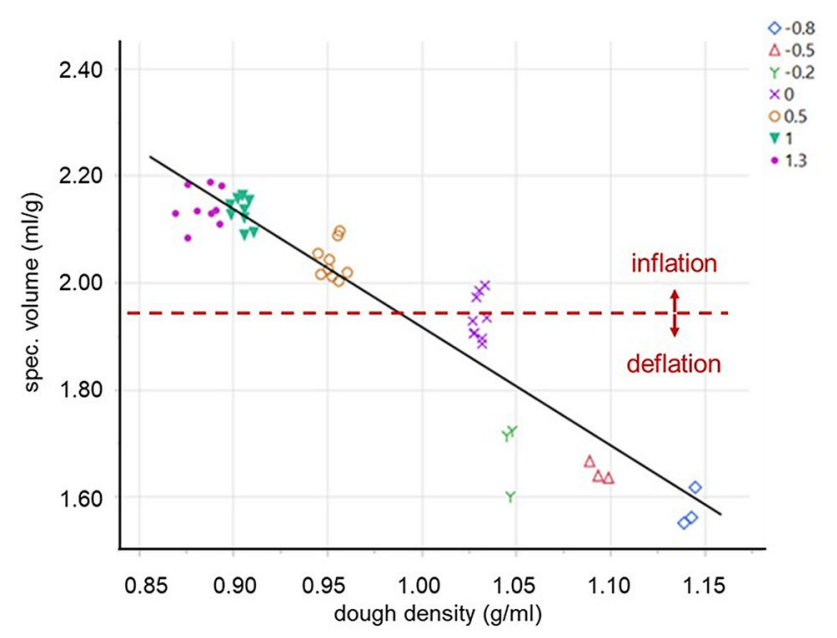

Fig. 7 Significant $(p<0.05)$ linear dependency between the specific bread volume and the gluten-free dough density after mixing with different headspace atmosphere pressures $\left(p_{\text {rel }}-80\right.$ to $\left.p_{\text {rel }} 130 \mathrm{kPa}\right)$ at $3000 \mathrm{rpm}$ for $8 \mathrm{~min} . R^{2}=0.876$

[30]. Consequently, finer gas bubbles should be present in the dough, which can expand during thermal processing and grow through biological gas entrapment by yeast cells. The 8 min mixing process was divided into a 1 st phase (overpressure)/2nd phase (negative pressure) mixing at different durations: 20/80 (384 s/96 s), 50/50 (240 s/240 s) and $80 / 20(96 \mathrm{~s} / 384 \mathrm{~s})$ at a mixing speed of $3000 \mathrm{rpm}$ for both phases and a overpressure of $p_{\text {rel }} 130 \mathrm{kPa}$ at the 1 st phase.
The results of this experiment showed a gas entrapment after the first mixing phase ( $p_{\text {rel }} 130 \mathrm{kPa}$ ) of $20 \%$, however, the application of a negative pressure afterwards led to a degassing of the dough. This effect was heightened, when a negative pressure of $-80 \mathrm{kPa}$ was used or the duration of the second phase was extended from $80 / 20$ to 20/80 (Fig. 8). This is in accordance with findings of Sadot et al. [30], who noticed a dependency of the gas volume fraction exclusively with the final pressure of the mixing process.

Despite the partial degassing of the dough (left part of Fig. 8), an extended second mixing phase (20/80) at different negative pressure levels $\left(p_{\text {rel }}-20 \mathrm{kPa}\right.$ to $\left.p_{\text {rel }}-80 \mathrm{kPa}\right)$ showed no negative effects on the specific volume of breads (middle) or a negative effect on the crumb hardness (right) in comparison to an equal first or second mixing phase (50/50) or elongated second mixing phase (80/20) (no significant differences between an elongated long first or second mixing phase, respectively). The poor correlation between dough stability and bread volume was already noticed by Correa, Pérez, and Ferrero on pectin supplemented dough and breads [31]. The longer first overpressure phase (80/20) does possibly slightly increase the dough temperature and consequently reduce the dough viscosity, so that the higher gas entrapment in the dough fraction during mixing cannot be transferred into the sponge matrix of the gluten-free bread [32]. In addition, the authors presume that just a partial degassing of gas bubbles occur during the second phase at elongated negative pressure, so that gas alveoli remained in the dough, which can expand by biological leavening processes and thermal steps, contributing to the final crumb structure [33]. 

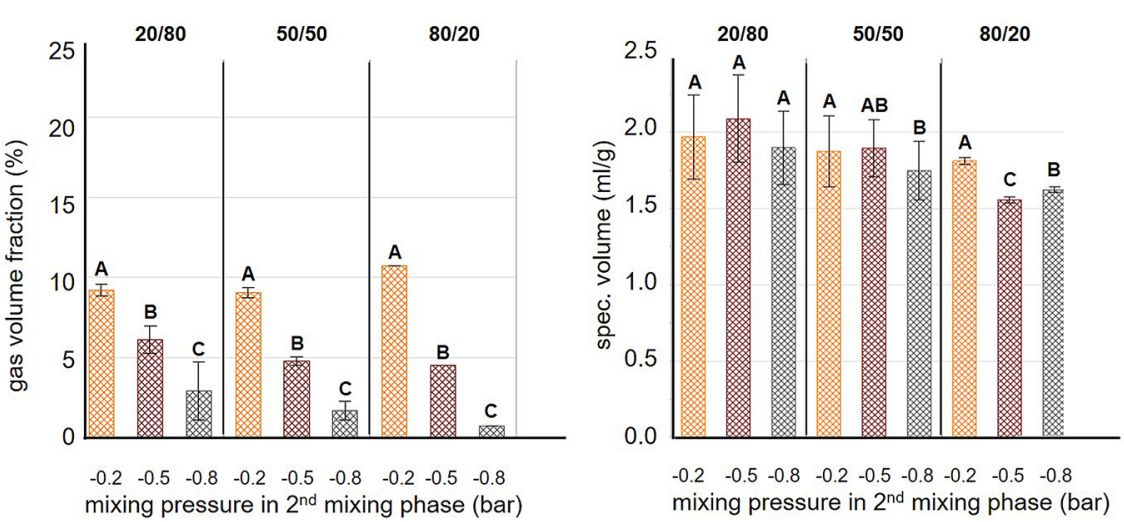

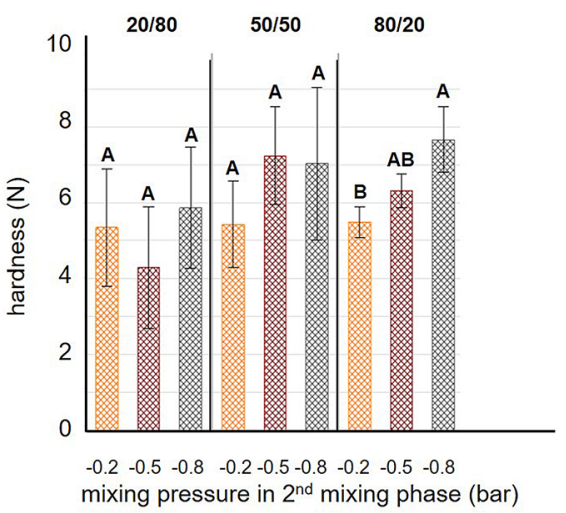

Fig. 8 Impact of mixing time in 2 phase mixing (1st phase/2nd phase: $20 / 80,50 / 50,80 / 20$ time, based on a 8 min mixing process) and relative negative mixing pressure in second mixing phase of $-20 \mathrm{kPa}$, $-50 \mathrm{kPa}$ and $-80 \mathrm{kPa}$ on gas volume fraction, spec. bread volume and crumb hardness at a mixing speed of $3000 \mathrm{rpm}$ for both phases and a overpressure during 1st mixing of $p_{\text {rel }} 130 \mathrm{kPa}$ and varied

Both mechanisms would minimize the effects between an elongated first (overpressure) mixing phase (80/20) and an elongated second (negative pressure) mixing phase (20/80). Thus, ratio of the duration of first to second mixing phase showed only limited effects.

However, the pressure of the second mixing phase was highly relevant: negative pressure during mixing should be avoided since higher bread volumes were gained without the application of negative pressure. Already the decrease in pressure from $p_{\text {rel }}-20 \mathrm{kPa}$ to $p_{\text {rel }}-80 \mathrm{kPa}$ caused a reduction in gas volume fraction in dough (for instance from $9.2 \pm 0.3 \%$ to $3.8 \pm 0.4 \%$ (20/80 first to second mixing phase)). The comparison with the one phase mixing continuously at $p_{\text {rel }} 130 \mathrm{kPa}$ demonstrated the enormous (negative) effects of the application of a negative pressure in the second mixing phase: the gas volume fraction in dough decreased from 23 to $1 \%$, the specific bread volume decreased from 2.2 to $1.6 \mathrm{ml} / \mathrm{g}$ and the crumb hardness increased from 4.2 to $7.8 \mathrm{~N}$, when mixing at overpressure $\left(p_{\text {rel }} 130 \mathrm{kPa}\right)$ was partially substituted by negative pressure of $p_{\text {rel }}-80 \mathrm{kPa}(80 / 20$ ratio) (compare Fig. 8 and Fig. 5).

The image analysis demonstrated the effects of the ratio of first to second mixing phase on the pore structure of the crumbs. Especially an extended first mixing phase (80/20) resulted in the formation of a very fine crumb structure containing small, homogenous distributed pores, whereby a short first mixing phase (20/80) caused the formation of bigger pores, which, however, were still homogenous distributed (Fig. 9). These results were unexpected, since it is known from the one phase 'Chorleywood bread process' that mixing below atmospheric pressure gives a fine pore structure and mixing above atmospheric pressure leads to an open cell structure [34]. Thus, the authors expected a negative pressure levels in the 2nd mixing phase: $p_{\text {rel }}-80 \mathrm{kPa}$, $p_{\text {rel }}-50 \mathrm{kPa}$ and $p_{\text {rel }}-20 \mathrm{kPa}$. Mean \pm std., $n=3$. Different letters demonstrate significant differences in gas volume fraction, spec. bread volume or crumb hardness ( $p$ values $<0.05$ ), identified by oneway ANOVA Tukey Test

finer pore structure with extended second (negative pressure) mixing phase. Since the data were achieved for only applying overpressure OR negative pressure from the 'Chorleywood bread process', they are not directly transferable to a two-phase mixing process. In addition, 'Chorleywood bread process' was developed and adapted for gluten-containing dough matrices, containing a gluten network to stabilize gas at negative pressure mixing of dough. This network is missing for gf dough, leading to an easier degassing of dough at negative pressure during mixing, why negative pressure come along with a lower specific bread volume. Furthermore, variations in the headspace atmosphere pressure reveal in gluten-containing matrices a physical (inflation/ deflation) AND a chemical (supported/impeded oxidation of thiol groups) effect, whereas only physical effects are mainly present in gluten-free dough. Nonetheless, if the crumb structure is the principle focus, negative pressure of the headspace atmosphere can be used to create desired finer crumb structures of gluten-free breads at lower specific bread volumes.

Further research is indispensable to elucidate gas bubble stabilization and crumb structure formation in a two-phase mixing process and a subsequent thermal processing step, to highlight differences between exclusively overpressure/ negative pressure and a combination of pressure steps during mixing.

\section{Conclusions}

The understanding of processing technologies and mechanical methods to entrap gas into gluten-free matrices is elementary to improve the bread volume and pore 


\section{mixing pressure in $2^{\text {nd }}$ mixing phase}
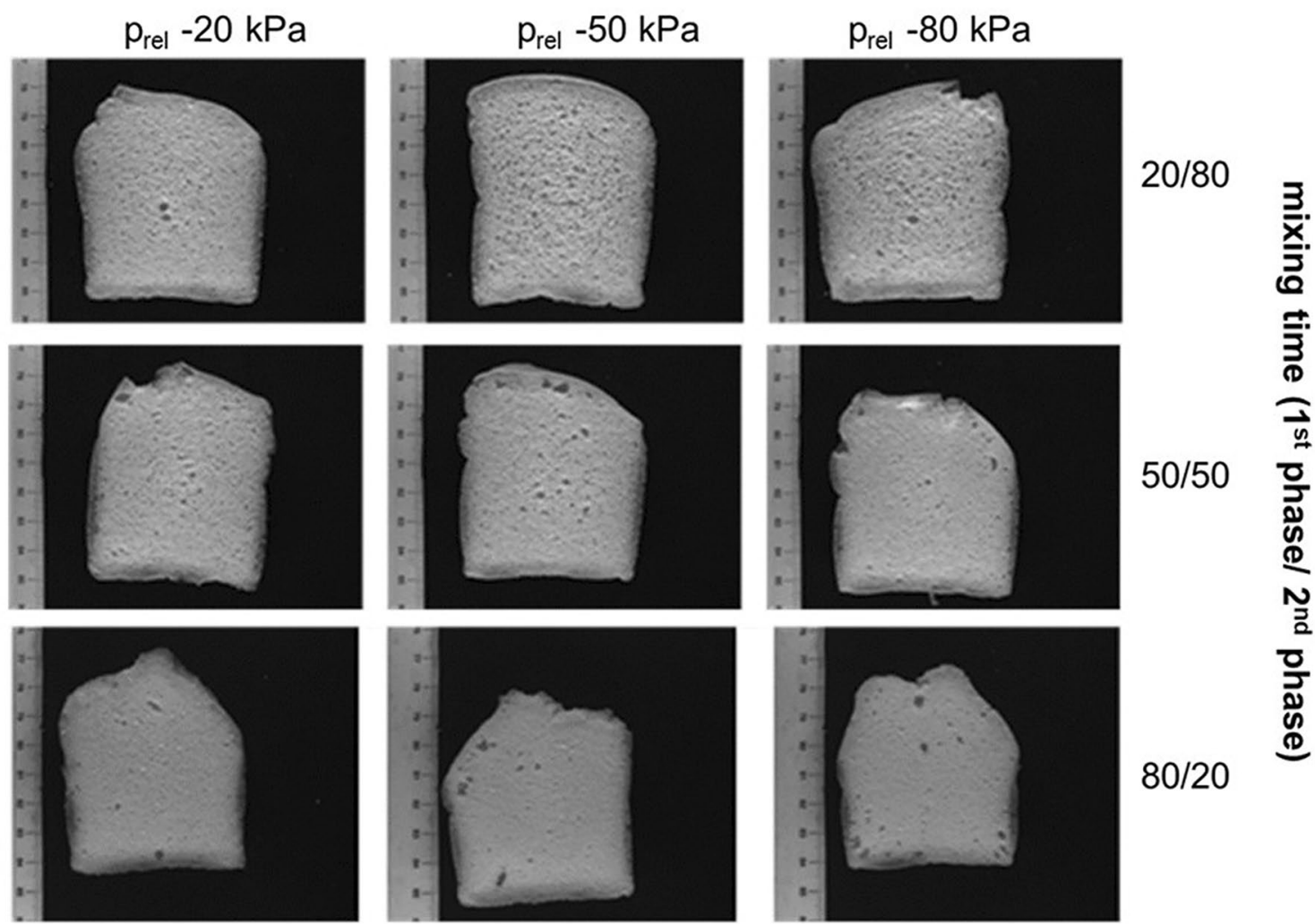

Fig. 9 Impact of mixing time in 2 phase mixing (1st phase/2nd phase: $20 / 80,50 / 50,80 / 20$ time, based on a 8 min mixing process) and relative negative mixing pressure in second mixing phase of $p_{\text {rel }}$

size distribution of gluten-free (baked) products. This study demonstrated that capturing gas into a gluten-free dough matrix can be enhanced by an excess pressure (compressed air) in the headspace atmosphere during mixing in a Stephans mixer, then the adaption of mixing parameters, as mixing speed or duration. Thereby, the gas volume fraction of the dough showed a significant relation to the specific volume of the gluten-free breads $\left(R^{2}=0.876\right)$, resulting in the reduction of the crumb hardness. The application of negative pressure in the headspace atmosphere during mixing was an adequate tool to create a finer pore size distribution (finer/bigger pores) in gluten-free (gf) crumbs, but simultaneously lower specific bread volume caused the degassing of gf dough. Further studies are necessary to assign alterations in the crumb structure to rheological changes of the dough and to evaluate the impact of the gas composition of the headspace atmosphere on the gas entrapping in dough and breads. The current results show the extensive potential of the quality control and improvement of gluten-free products without the addition of food additives using a modified headspace atmosphere during mixing.
$-20 \mathrm{kPa}, p_{\text {rel }}-50 \mathrm{kPa}$ and $p_{\text {rel }}-80 \mathrm{kPa}$ on the pore size distribution in crumbs at a mixing speed of $3000 \mathrm{rpm}$ for both phases and a overpressure during 1 st mixing of $p_{\text {rel }} 130 \mathrm{kPa}$

Supplementary Information The online version contains supplementary material available at https://doi.org/10.1007/s00217-021-03793-z.

Acknowledgements The authors would like to thank the 'Weihenstephaner Institut für Getreideforschung' (WIG) for enabling this research, as well as Müller's Mühle GmbH (Gelsenkirchen, Germany) for the supply of rice flour.

Funding Open Access funding enabled and organized by Projekt DEAL. This IGF Project of the FEI $(18619 \mathrm{~N})$ was supported via AiF within the programme for promoting the Industrial Collective Research (IGF) of the German Ministry of Economic Affairs and Energy (BMWi), based on a resolution of the German Parliament.

Conflict of Interest The authors declare no conflict of interest.

Open Access This article is licensed under a Creative Commons Attribution 4.0 International License, which permits use, sharing, adaptation, distribution and reproduction in any medium or format, as long as you give appropriate credit to the original author(s) and the source, provide a link to the Creative Commons licence, and indicate if changes were made. The images or other third party material in this article are included in the article's Creative Commons licence, unless indicated otherwise in a credit line to the material. If material is not included in the article's Creative Commons licence and your intended use is not permitted by statutory regulation or exceeds the permitted use, you will 
need to obtain permission directly from the copyright holder. To view a copy of this licence, visit http://creativecommons.org/licenses/by/4.0/.

\section{References}

1. Elgeti DD (2017) Aeration strategies and identification of foam stabilization mechanisms for gluten-free dough systems. Technical University of Munich

2. Mancebo CM, San Miguel MÁ, Martínez MM, Gómez M (2015) Optimisation of rheological properties of gluten-free doughs with HPMC, psyllium and different levels of water. J Cereal Sci 61:8-15. https://doi.org/10.1016/j.jcs.2014.10.005

3. Föste M, Jekle M, Becker T (2017) Structure stabilization in starch-quinoa bran doughs: the role of water availability and gelatinization. Carbohydr Polym 174:1018-1025. https://doi.org/ 10.1016/j.carbpol.2017.06.068

4. Paulik S, Docx R, Becker T, Jekle M (2020) Texturmodifikation glutenfreier Backwaren. Cereal Technol 2:138-143

5. Bender D, Regner M, D’Amico S, Jäger H, Tömösközi S, Schoenlechner R (2018) Effect of differently extracted arabinoxylan on gluten-free sourdough-bread properties. J Food Qual 2018:1-10. https://doi.org/10.1155/2018/5719681

6. Wronkowska M, Haros M, Soral-Śmietana M (2013) Effect of starch substitution by buckwheat flour on gluten-free bread quality. Food Bioprocess Technol 6:1820-1827. https://doi.org/10. 1007/s11947-012-0839-0

7. Bravo-Núñez Á, Sahagún M, Gómez M (2019) Assessing the importance of protein interactions and hydration level on proteinenriched gluten-free breads: a novel approach. Food Bioprocess Technol 12:820-828. https://doi.org/10.1007/s11947-019-02258-2

8. Elgeti D, Yu L, Stüttgen A, Jekle M, Becker T (2017) Interrelation between mechanical and biological aeration in starch-based gluten-free dough systems. J Cereal Sci 76:28-34. https://doi.org/ 10.1016/j.jcs.2017.05.008

9. Lammers V (2016) A novel technology to tailor foam structure in gluten-free bakery product systems. ETH Zürich

10. Sciarini LS, Ribotta PD, León AE, Pérez GT (2010) Influence of gluten-free flours and their mixtures on batter properties and bread quality. Food Bioprocess Technol 3:577-585. https://doi.org/10. 1007/s11947-008-0098-2

11. Campbell GM, Mougeot E (1999) Creation and characterisation of aerated food products. Trends Food Sci Technol 10:283-296. https://doi.org/10.1016/S0924-2244(00)00008-X

12. Elgeti D, Peng L, Jekle M, Becker T (2017) Foam stabilization during processing of starch-based dough systems. Innov Food Sci Emerg Technol 39:267-274. https://doi.org/10.1016/j.ifset.2016. 12.012

13. Bender D, Gratz M, Vogt S, Fauster T, Wicki B, Pichler S, Kinner M, Jäger H, Schoenlechner R (2019) Ohmic heating — a novel approach for gluten-free bread baking. Food Bioprocess Technol 12:1603-1613. https://doi.org/10.1007/s11947-019-02324-9

14. Chin NL, Campbell GM (2005) Dough aeration and rheology: Part 1. Effects of mixing speed and headspace pressure on mechanical development of bread dough. J Sci Food Agric 85:2184-2193. https://doi.org/10.1002/jsfa.2236

15. Trinh L (2013) Gas cells in bread dough. Thesis, at the University of Manchester, School of Chemical Engineering and Analytical Science

16. Cauvain SP, Young LS (2006) Chorleywood bread process fundamentals. In: The chorleywood bread process. Elsevier, pp 17-23

17. Schünemann C (2006) Lernfelder der Bäckerei - Produktion Praxis-Theorie-Lehrwerk für die Berufsausbildung zum Bäcker, zur Bäckerin. Gildebuchverl (ISBN 9783773401656$)$
18. Wang S, Austin P, Bell S (2011) It's a maze: the pore structure of bread crumbs. J Cereal Sci 54:203-210. https://doi.org/10.1016/j. jcs.2011.05.004

19. Gao J, Koh AHS, Tay SL, Zhou W (2017) Dough and bread made from high- and low-protein flours by vacuum mixing: Part 1: Gluten network formation. J Cereal Sci 74:288-295. https://doi.org/ 10.1016/j.jcs.2017.03.008

20. Cauvain, Stanley P, Young LS (2007) Technology of breadmaking. Springer, Boston

21. Eggert A (2018) Fast laboratory micro-CT of food foams: principle, experimental setup for foam characterization and stability. Dr. Hut, München (ISBN 978-3843936637)

22. Gómez M, Talegón M, de la Hera E (2013) Influence of mixing on quality of gluten-free bread. J Food Qual 36:139-145. https:// doi.org/10.1111/jfq. 12014

23. Macritchie F (2007) Mechanical degradation of gluten proteins during high-speed mixing of doughs. J Polym Sci Polym Symp 49:85-90. https://doi.org/10.1002/polc.5070490108

24. Massey AH, Khare AS, Niranjan K (2008) Air inclusion into a model cake batter using a pressure whisk: development of gas hold-up and bubble size distribution. J Food Sci 66:1152-1157. https://doi.org/10.1111/j.1365-2621.2001.tb16097.x

25. Yildiz E, Guner S, Sumnu G, Sahin S, Oztop MH (2018) Monitoring the effects of ingredients and baking methods on quality of gluten-free cakes by time-domain (TD) NMR relaxometry. Food Bioprocess Technol 11:1923-1933. https://doi.org/10.1007/ s11947-018-2152-z

26. Paulik S, Jekle M, Becker T (2019) A review: reverse approach to analyze the impact of starch modification on the inflation and gas holding properties of wheat-based matrices. Trends Food Sci Technol 91:231-239. https://doi.org/10.1016/J.TIFS.2019.07.031

27. Jekle M, Becker T (2012) Frischhaltung bei Weizenbroten. Backtechnik Eur 3:62-65

28. Tan MC, Chin NL, Yusof YA (2012) A Box-Behnken design for determining the optimum experimental condition of cake batter mixing. Food Bioprocess Technol 5:972-982. https://doi.org/10. 1007/s11947-010-0394-5

29. Belitz H-D, Grosch W, Schieberle P (2008) Lehrbuch der Lebensmittelchemie : mit 634 Tabellen. Springer (ISBN 9783540732020)

30. Sadot M, Cheio J, Le-Bail A (2017) Impact on dough aeration of pressure change during mixing. J Food Eng 195:150-157. https:// doi.org/10.1016/j.jfoodeng.2016.09.008

31. Correa MJ, Pérez GT, Ferrero C (2012) Pectins as breadmaking additives: effect on dough rheology and bread quality. Food Bioprocess Technol 5:2889-2898. https://doi.org/10.1007/ s11947-011-0631-6

32. Mir SA, Shah MA, Naik HR, Zargar IA (2016) Influence of hydrocolloids on dough handling and technological properties of glutenfree breads. Trends Food Sci Technol 51:49-57. https://doi.org/ 10.1016/j.tifs.2016.03.005

33. Mills ENC, Wilde PJ, Salt LJ, Skeggs P (2003) Bubble formation and stabilization in bread dough. Food Bioprod Process 81:189193. https://doi.org/10.1205/096030803322437956

34. Cauvain SP, Clark RH (2019) Baking technology and nutrition: towards a healthier world. Wiley

Publisher's Note Springer Nature remains neutral with regard to jurisdictional claims in published maps and institutional affiliations. 